\title{
COASTAL MANAGEMENT AND DISASTER PLANNING ON THE BASIS OF FLOOD RISK CALCULATIONS
}

\author{
Tina Mertens ${ }^{1}$, Toon Verwaest ${ }^{2}$, Rosalia Delgado $^{2}$, Koen Trouw ${ }^{3}$, Leo De Nocker ${ }^{4}$
}

Recent studies showed that one third of the Belgian coastline is not sufficiently protected against severe storm events. Therefore coastal protection plans are set up to assure a minimum safety standard for the entire coastline. Flood risk calculations constitute the main input parameter for the concept and planning phases. Since $100 \%$ safety can never be guaranteed, contingency plans are constructed to reduce the remaining flood risks. Flood risk calculations are a powerful communicative and operational instrument to use between engineers and experts on the field, thus forming the link between coastal management and disaster planning.

Keywords: coastal protection; flood risk; contingency planning

\section{INTRODUCTION}

The Belgian coast is situated at the southern part of the North Sea between The Netherlands and France. The coastline is $67 \mathrm{~km}$ long consisting mostly of sandy beaches with sea walls in front of the cities and dunes in between. There are 4 harbours at Nieuwpoort, Oostende, Blankenberge and Zeebrugge and a tidal inlet at the border with The Netherlands, called the Zwin.

This small stretch of land is intensively used by different stakeholders. Aside from housing the coastline is landmarked by nature reserves, tourism and industry. Nevertheless, the low-lying polders in the hinterland form a 15 kilometer wide flood prone area in which about 400.000 people live (Fig. 1). This area is situated about 2 meters under the level of an average storm and without appropriate coastal protection it would flood every year.

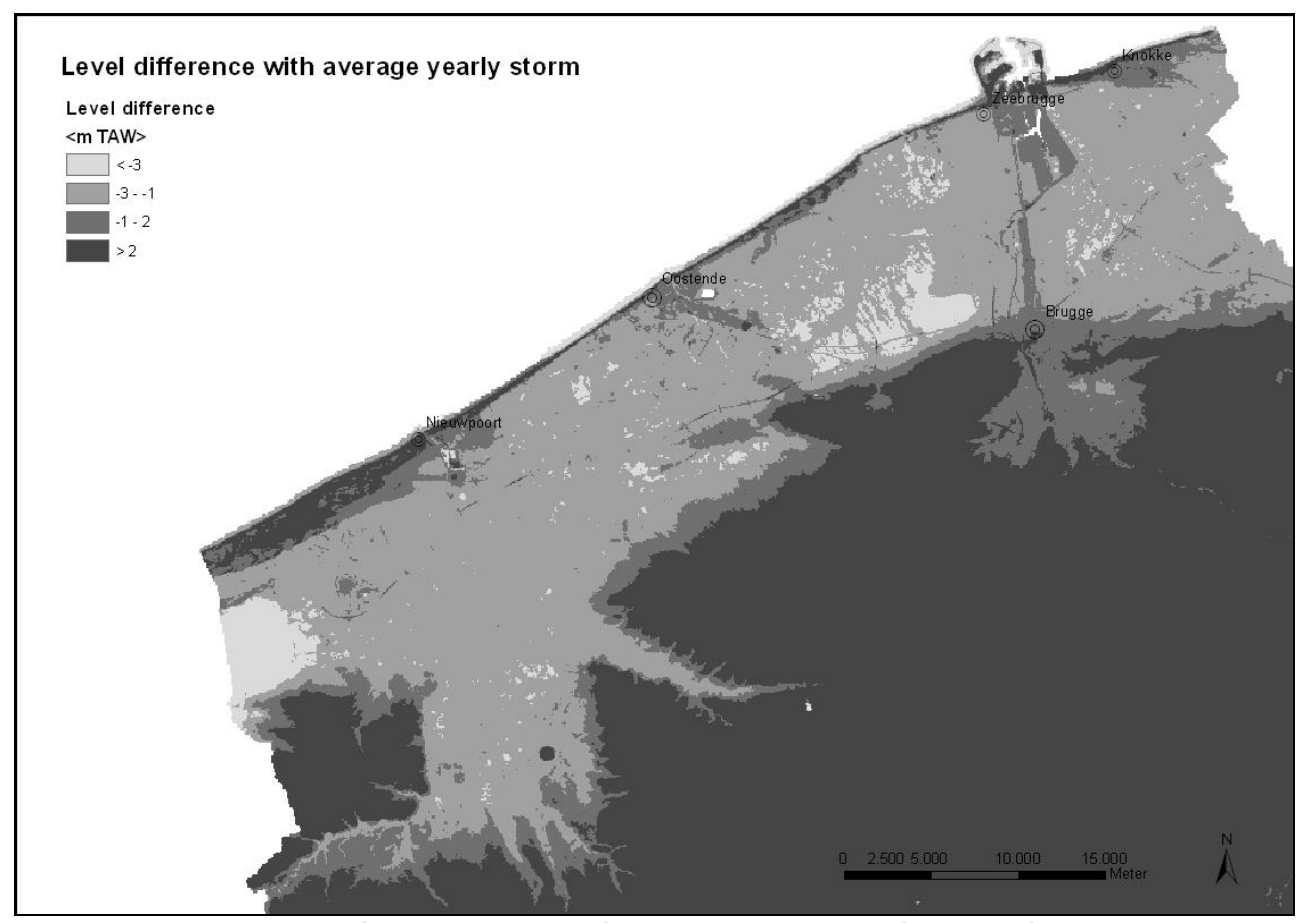

Figure 1. The low-lying polders at the Belgian coastline

Recent studies showed that one third of the coastline is not sufficiently protected against severe storm events. Therefore coastal protection plans are set up to assure a minimum safety standard for the

\footnotetext{
${ }^{1}$ Belgian Coastal Division, Vrijhavenstraat 3, Oostende, 8400, Belgium

${ }^{2}$ Flanders Hydraulics Research, Berchemlei 115, Antwerpen, 2100, Belgium

3 International Marine and Dredging Consultants, Coveliersstraat 15, Antwerpen, 2600, Belgium

${ }^{4}$ Flemish Institute for Technological Research (VITO), Boeretang 200, Mol, 2400, Belgium
} 
entire coastline. Flood risk calculations constitute the main input parameter for the concept and planning phases.

Since $100 \%$ safety can never be guaranteed, contingency plans are constructed to reduce the remaining flood risks.

\section{CHAIN OF SAFETY EMBRACED BY THE FLOOD DIRECTIVE}

Since flooding disasters do not stop at local, regional or even national borders, and neither do the effects of such disasters, transnational cooperation in contingency planning is very important.

In the framework of a European project Chain of Safety knowledge and expertise for disaster planning was exchanged with partner countries from the North Sea Region. Policy makers, engineers and practitioners worked together in order to find a balance and common understanding between the different interaction levels of the chain of safety.

The chain of safety has several links (Fig. 2). These links differ from each other in their time scope (from long term prevention to medium-term recovery) and aim. Five different links can be distinguished:

- Pro-action: the elimination of structural causes of danger, thereby preventing the development of dangerous situations.

- Prevention: the minimization of risks and the restriction of the consequences of any accidents that occur.

- Preparation: the preparations for the control of accidents, disasters and crises.

- Response: the operational control of dangerous situations that have occurred, including the provision of the necessary assistance.

- Recovery: the concluding link in the safety chain. Recovery focuses on the return to the normal situation, together with evaluations that result in procedural improvements.

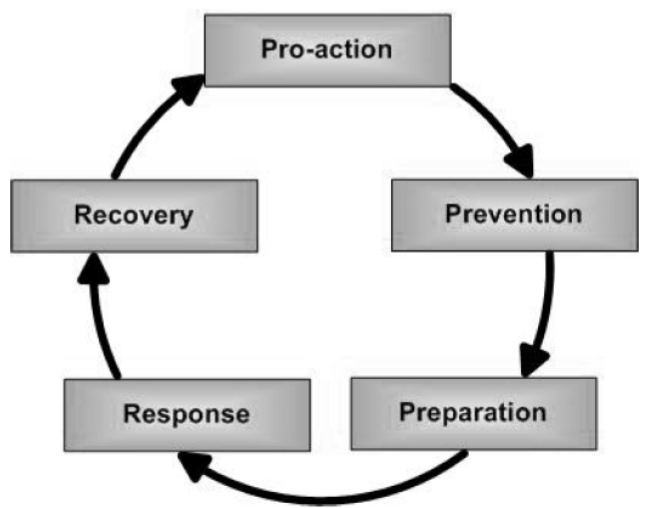

Figure 2. Chain of Safety

The concept of this chain of safety approach is embraced by the EU Flood Directive (2007/60/EC). In this directive it is stated that "Flood risk management plans should focus on prevention, protection and preparedness". In other words, coastal defences are not sufficient: the three first shackles of the safety chain are crucial to manage flood risks. Flood risk calculations form the basis for the follow-up of the whole chain of safety.

\section{FLOOD RISK CALCULATIONS AS EVALUATION TOOL}

Flanders Hydraulics Research has worked out a methodology for calculating the flood risks for several extreme storms according to Verwaest et al (2008) to estimate the number of casualties and economic damage at the seafront and in the hinterland.

These flood risk calculations are used as an input for setting up coastal management plans and to work out contingency and evacuation plans (Fig. 3). 


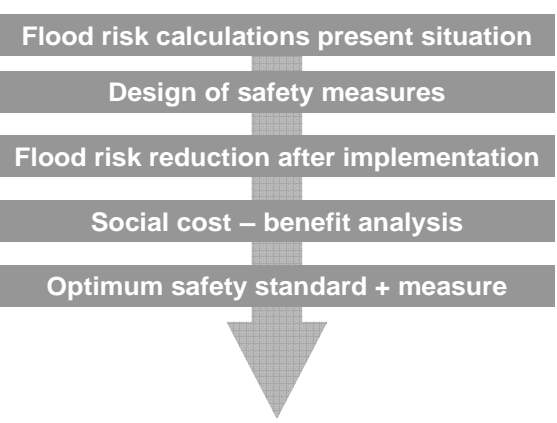

a.

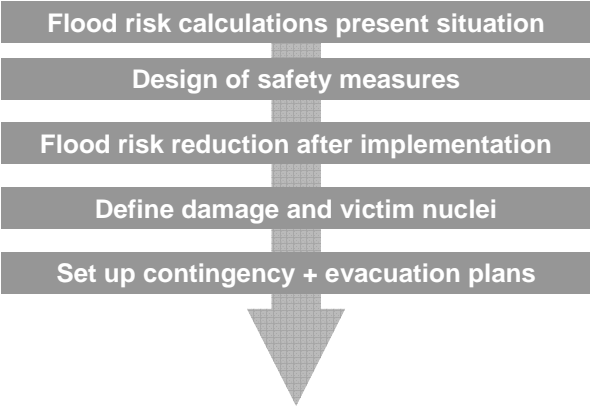

b.

Figure 3. Scheme for coastal management on the left (a) and disaster planning on the right (b).

\section{Input for coastal management}

In 2007, the Belgian Coastal Division initiated an Integrated Master Plan for Coastal Safety to provide a minimum safety standard of once in 1000 year for the entire coastline. As explained in Mertens et al (2008) this plan will form the basis for the development of the seafront along the Belgian coast in the nearby and distant future (up till 2050) with safety against flooding as its main objective.

The combined evaluation of environmental impacts, flood risk reductions and costs versus benefits will support the selection of integrated defence measures for every weak link. The implementation phase of the Master Plan for Coastal Safety is planned between 2010 and 2015.

\section{Weak links}

All weak links have been determined based on stability and breaching calculations of the sea defences. According to Verwaest et al (2008) a worst credible storm can result in 3000 casualties, mainly on the sea defence itself, and $€ 3$ billion economic damage. At all harbours and several coastal communities quay walls and dyke levels are too low, resulting in overflow and breaches during extreme storms, thus causing major flooding for dozens of kilometers land inwards (Fig. 4).

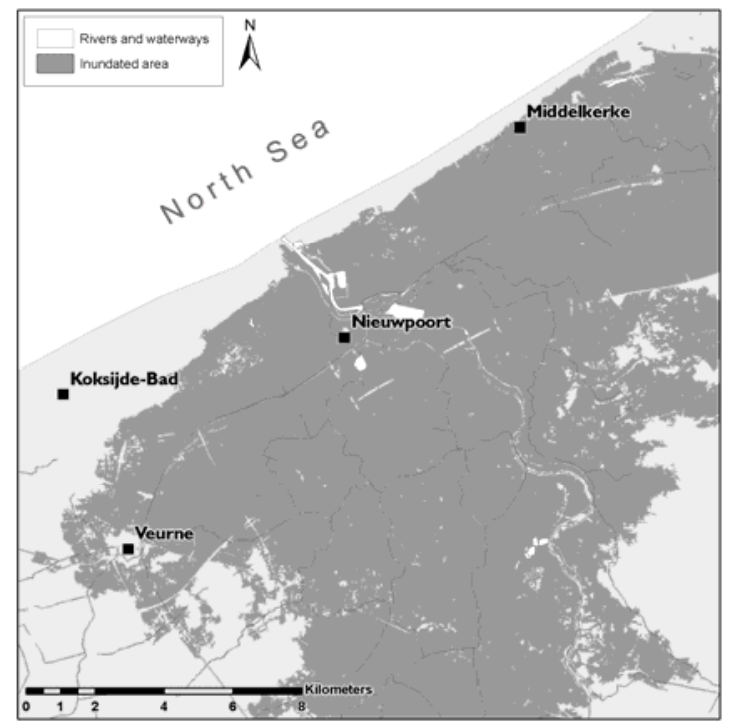

Figure 4. Flooding of the western Belgian coastal zone due to breaches in the sea defences caused by an extreme storm event (simulated with the MIKEFLOOD software package).

The results indicate that one third of the coastline needs to be reinforced to withstand extreme storm floods, providing a minimum safety standard of once in 1000 year.

Locks and weirs need special attention, as structural strengthening or an adjusted operation is needed for these structures to resist the impact of water forces during storms. The contribution of each 
weak link to the overall number of risks enables us to prioritize specific defence measures in the final Master Plan.

As $100 \%$ safety can never be guaranteed, risk calculations are used to evaluate the risk reduction from and remaining risk after the implementation of a defence measure, which are used as an input for the social cost-benefit analysis.

\section{Evaluation of protection measures}

Potential protection measures such as beach or dune nourishments, storm return walls, stilling wave basins and storm flood barriers have been selected and are studied to account for their environmental impacts in an Environmental Impact Assessment (EIA), costs vs. benefits and potential impacts on tourism. This paper will only highlight the latter two.

In the social cost benefit analysis the costs are calculated as a combination of investment and operational (maintenance) costs. Beach nourishments for examples have to be maintained every 5 years, while storm return walls can be constructed to last for 50 years or more and thus need reinvestment after a certain period.

For the benefits different input parameters are selected. First the safety benefit is calculated as the difference between the current flood risk and the remaining flood risk, after implementation of the safety measures. A distinction is made between the avoided risk for material damage and the avoided risk for victims. The estimate of the value of human life is based on figures about the willingness to pay to reduce a certain risk: a household wants to pay 2,4 euro per year to reduce the annual risk for a deadly accident to one in a million. These figures match with recommendations for the value of human life in the context of traffic accidents in Flanders Region and European studies as the HEATCO project.

In a second step an estimate is made for the recreation benefit of certain protection measures. The value of an extra surface of dry beach or a second dyke is rated. Based on inquiries of tourists it was determined that $4 €$ per extra square meter of dry beach is a minimum rate that can be included. Because no further details for the value of dykes are available the same rate was given to an extra surface of dyke.

These values make is possible to determine whether each safety measure earns itself back after a certain period in time. Projects that have a bad benefit-cost ratio, i.e. lower than 1 , within the time frame of the study (the Master Plan has a time horizon till the year 2050) are negatively rated. To include extra recreation values often means that certain measures get a positive rate in the end since they earn themselves back more quickly. This is shown in the next example (Table 1). Five safety measures are studied for the coastal town of Mariakerke: high beach, low beach (LB), low beach in combination with a storm return wall of 0,60 meter, low beach in combination with a storm return wall of 1,20 meter and a low beach in combination with a second dyke. As shown in Table 1 only a low beach with a high storm return wall earns itself back till 2050. If recreation values are incorporated, all measures earn themselves back from 2040 onwards. 


\begin{tabular}{|c|c|c|c|c|c|}
\hline Benefit/cost & High beach & Low beach (LB) & $\mathrm{LB}+0,60 \mathrm{~m}$ wall & $\mathrm{LB}+1,2 \mathrm{~m}$ wall & LB + 2nd dyke \\
\hline till 2020 & 0,07 & 0,09 & 0,11 & 0,15 & 0,09 \\
\hline till 2030 & 0,24 & 0,29 & 0,35 & 0,48 & 0,30 \\
\hline till 2040 & 0,37 & 0,47 & 0,55 & 0,76 & 0,48 \\
\hline till 2050 & 0,49 & 0,61 & 0,73 & 1,00 & 0,63 \\
\hline till 2060 & 0,58 & 0,73 & 0,88 & 1,21 & 0,76 \\
\hline till 2080 & 0,74 & 0,94 & 1,11 & 1,51 & 0,97 \\
\hline till 2100 & 0,87 & 1,11 & 1,31 & 1,77 & 1,14 \\
\hline till 2110 & 0,93 & 1,18 & 1,39 & 1,89 & 1,22 \\
\hline \multicolumn{6}{|c|}{ With recreation value } \\
\hline till 2020 & 0,20 & 0,24 & 0,26 & 0,30 & 0,20 \\
\hline till 2030 & 0,66 & 0,78 & 0,85 & 0,98 & 0,65 \\
\hline till 2040 & 1,04 & 1,25 & 1,34 & 1,54 & 1,03 \\
\hline till 2050 & 1,36 & 1,63 & 1,76 & 2,03 & 1,36 \\
\hline till 2060 & 1,64 & 1,97 & 2,12 & 2,46 & 1,63 \\
\hline till 2080 & 2,09 & 2,52 & 2,69 & 3,07 & 2,09 \\
\hline till 2100 & 2,45 & 2,96 & 3,17 & 3,61 & 2,46 \\
\hline till 2110 & 2,61 & 3,15 & 3,37 & 3,84 & 2,61 \\
\hline
\end{tabular}

Since benefits can not always be expressed in monetary values, expert judgement was used to evaluated these non-monetary values. They mainly consist of effects on the attractiveness of the sea dykes and beaches caused by safety measures. The impact on the open sea view caused by a storm return wall on top of a sea dyke can be used as an example. A public inquiry for evaluating these impacts was performed with inhabitants and tourists in several coastal towns along the Belgian coastline.

\section{Optimum safety standard and measures}

To determine the optimum safety standard results of the social cost benefit analysis (SCBA) can be used: until which safety level benefits exceed costs? A distinction between the value of assets and the value of human life is needed: the optimal safety standard can differ from place to place thus implying a differentiated safety standard for people living along the coastline. Zones where flood risks are higher will normally have a higher safety standard. If equal protection for all people has to be guaranteed a minimum safety level for the entire coastline needs to be defined.

To justify high safety standards for occasional events such as storm impacts a difference needs to be made between the protection of individuals and groups.

The number of victims that may occur during a storm is not socially acceptable. Figure 5 shows the Belgian criterion, in force since 2006, for external group risk for companies that produce highly explosive materials. It reflects essentially our social aversion to major disasters involving mass casualties in a place and / or by an accident.

Thus, a comparison can be made between the victims of a super storm and those that may occur during an explosion. Both events can cause a high number of victims. This contrasts with the annual number of fatalities caused by traffic accidents. Each year traffic demands many deaths, spread over several separate events.

The group risk is displayed as a curve in a graph with two logarithmic scaled axes, called the risk curve. The vertical axis is the probability of occurrence of an event (per year). Plotted on the horizontal axis is the (minimum) number of expected casualties. This risk curve shows the relationship between the size of the group (N) and probability (f) that at one time a group of at least that size perishes. 
For every coastal protection measure a risk curve is drawn: the number of casualties is calculated for several storms with a different probability of occurrence. A risk curve is drawn for the reference year of the Master Plan (marked as "Risk anno 2000") and the risk is calculated for the zero option in 2050 (marked as "Risk anno 2050"). The zero option includes the continuation of current coastal policy, without the realisation of the Master Plan. The graph shows that a 250 year storm $(\approx$ storm of 1953) today would cause 23 deaths and a 1000 year storm event 146.

The criterion for societal risk (marked as "Criterion external group risk") defines two zones in this (fN) graph. To meet the requirements of the external criterion, the risk curve should lie on the left side of the graph in the zone marked as "protected". If the remaining risk on casualties is too high (right side of the graph), measures need to be taken in order to reduce this risk. These measures consist of protection measures (risk is reduced to the left side of the graph = "pro-action" phase) or evacuation which has to be prepared by the set-up of contingency plans ("preparation" phase).

To reduce the group risk and thus the number of deaths coastal protection measures are compiled for each weak link. The reduction of societal risk depends on the combination of coastal protection measures. The range of the reduction of risk is indicated by two curves marked as "Remaining risk Maximum reduction" and "Remaining risk Minimum reduction". They respectively indicate the results for the combination of protection measures which realizes a maximum and minimum risk reduction. It is noted that both curves always have a remaining risk located on the right side of the graph, i.e. the risk for the heaviest storms. The graph shows that, except for very severe storms, the societal risk can be reduced to acceptable quantities.

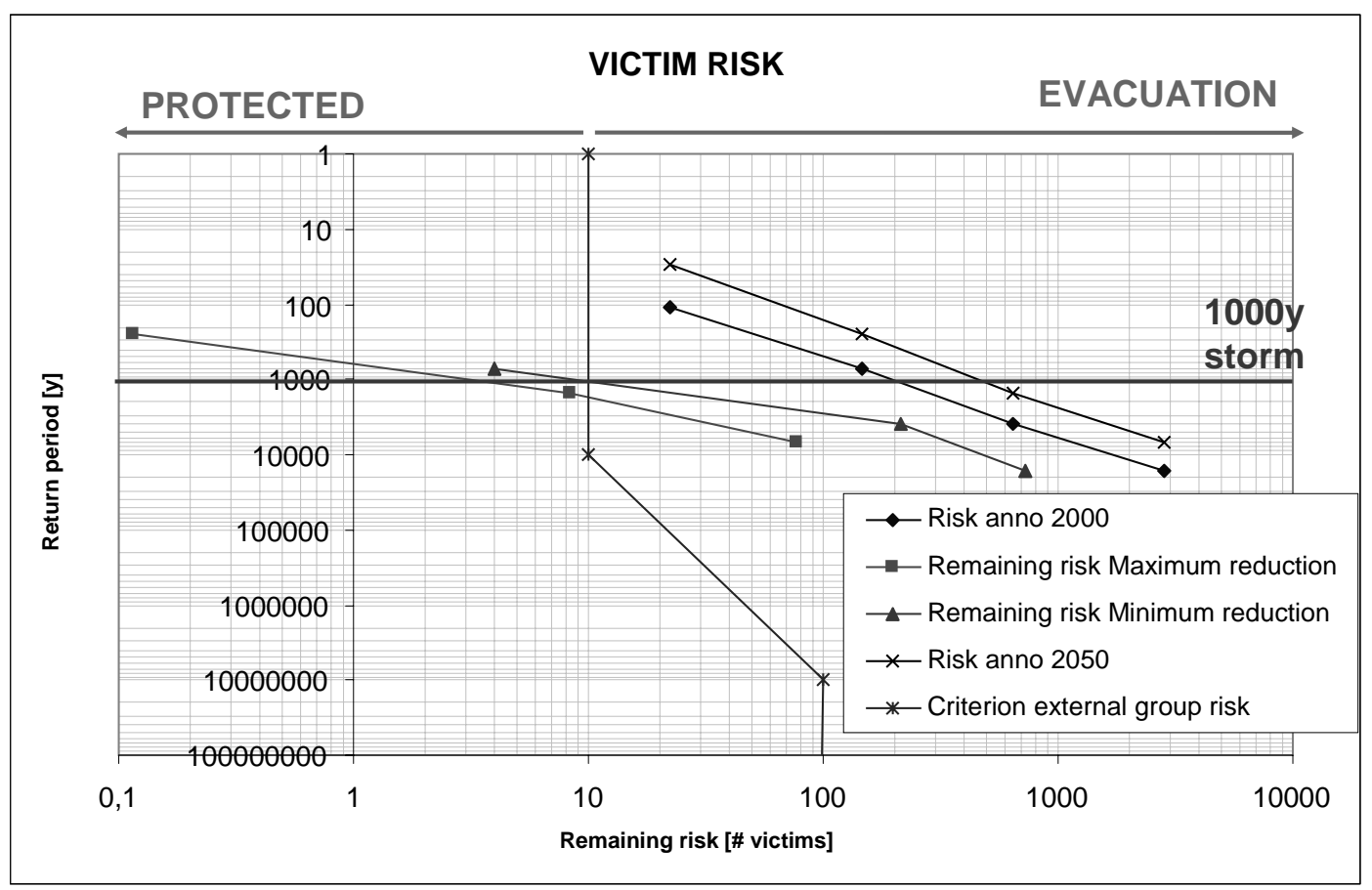

Figure 5. Criterion for external group risk.

To design optimal safety measure, results of different evaluation methods are used in the framework of the Master Plan. A combination is made between the results of the SCBA and the EIA, plus expert judgement for the evaluation of non-monetary values.

\section{Risk based contingency planning}

In the past contingency plans for flooding were mainly based on the principle "Where can we shelter the most people?" without taking into account the vulnerability of these areas. Current flood risk calculations provide specific information about potential floodable areas and casualty numbers in the hinterland and on the sea defence itself during extreme storms. This allows us to identify which coastal communities are more vulnerable and to define adequate procedures for the evacuation of 
citizens. A regional contingency plan for flooding is being set up based on these results in order to integrate and harmonize actions that have to be taken at the local level. This plan is being developed in cooperation with the Province of West Flanders and governmental organisations responsible for rivers and waterways.

\section{Priority areas (nuclei) for evacuation}

A study was performed by Meire et al (2010) which aimed at visualizing the spatial distribution of victim risks in so called 'victim nuclei' or 'victim core areas'. The study focuses on observation zones ('aandachtszones'), that are related to weak links in the coastal defence, and observation areas ('aandachtsgebieden'), that are flooded as a consequence of breaches or wave overtopping of the coastal protection constructions during different super storm events.

The visualization of vulnerability differentiation within the inundated areas highly depends on the classification method applied to the available geographical data, as it leads to spatial variation of the map content. The current data were processed in a GIS environment that offered seven discretization methods, allowing to identify none, one or various local subareas in which high victim concentrations could be found. The study aimed at defining 'optimal' victim nuclei, corresponding to the identification of 'optimal' class boundaries.

It was assumed that theoretically, a nucleus could be defined when more than $50 \%$ of the total number of victims was located in an area that, in proportion to the total flooded area, covered a smaller part (i.e. $<50 \%$ of studied area or zone). It should be noted that the percentages and respective nuclei are not to be interpreted as absolute results, as they give an indication of the most vulnerable subzones of the study areas. The methodology was applied in such a way that each victim nucleus took up equal to or more than $90 \%$ of the total expected number of victims in the respective study area (Fig. 6). Such a refinement of victim variation without taking (spontaneous or organized) evacuation into account will make it possible in the future research phase to delineate priority evacuation areas.

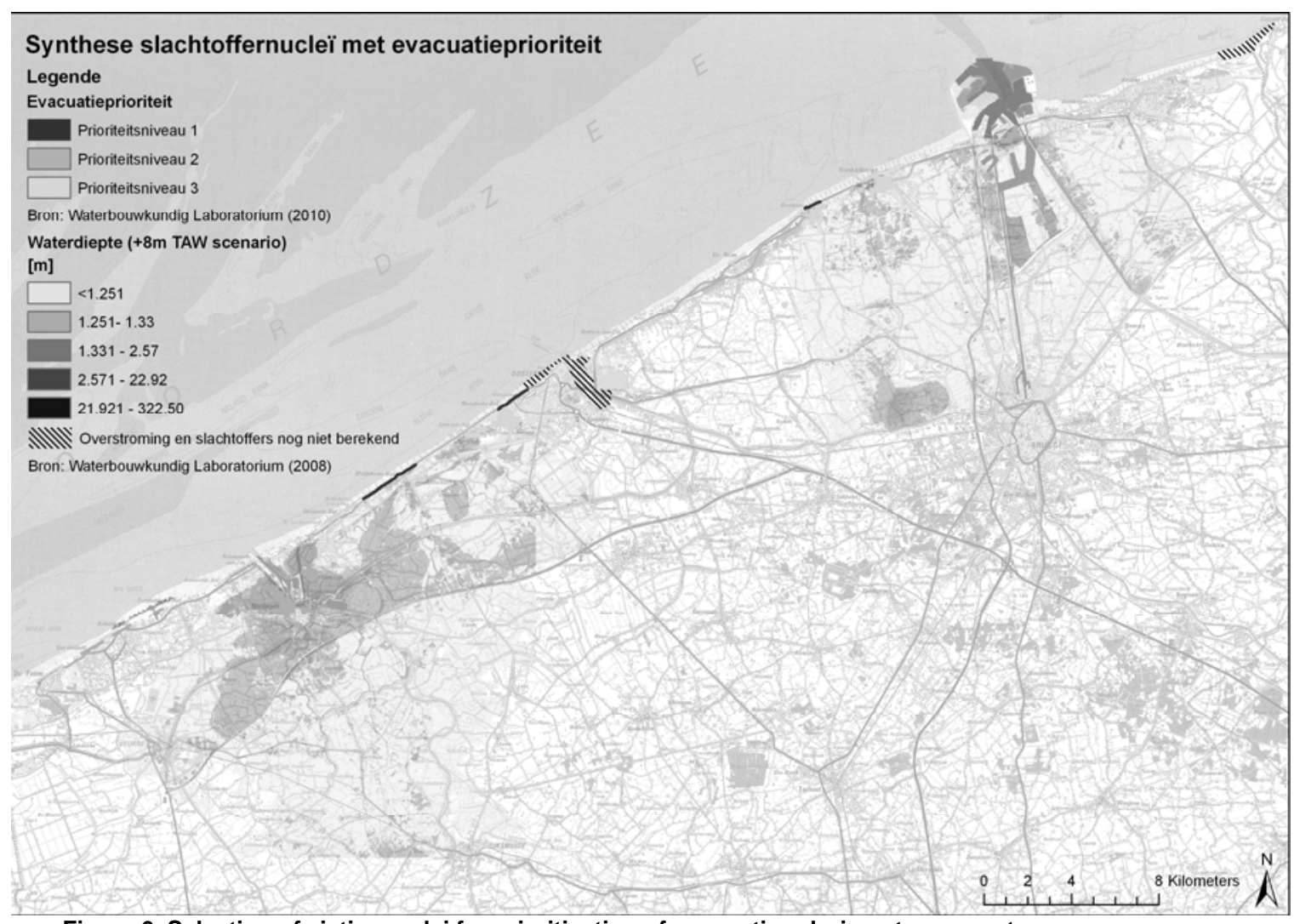

Figure 6. Selection of victim nuclei for prioritisation of evacuation during storm events 


\section{Flood risk calculations as a communicative and operational tool}

Flood risk calculations proved to be a useful tool in setting up contingency plans. The impact of several storm events can be shown on flood risk maps, thus providing input for drawing up different evacuation maps. The impact of a worst credible storm gives crucial information for the operational teams active on the field during storm events. Some examples for which flood risk calculations are used in contingency planning:

- Defining priority areas for evacuation;

- Localising possible evacuation routes and shelters;

- Drawing up perimeters;

- Choosing between horizontal vs. vertical evacuation;

- Communication tool between engineers and experts on the field.

- Information towards the public;

Having the correct scenario in place in case a storm may occur is of course not sufficient in disaster planning. Knowing who is involved and performing exercises is often more important. Managers, planners and experts on the field need to communicate in the same language. Visual information, such as flood (risk) maps, can help to improve this dialogue.

\section{FLOOD DIRECTIVE}

As an extra input for disaster planning along the seaside, combined flood risk calculations for sea and river flooding as well as cross border flooding are taken into account for the implementation of the European Flood Directive. In this perspective a first attempt was made in the framework of the European projects COMRISK and Safecoast to link different flood risk models and develop cross border flood risk maps. Recent flood risk calculations for the master plan will be evaluated and compared with Dutch data as a starting point for future European flood risk maps.

\section{REFERENCES}

Meire, E., Verwaest T., Reyns J., Mertens, T. 2010. Detailed localization of potential victims in nuclei for superstorm events at the Belgian coast, NCK days 2010.

Mertens, T., DeWolf P., Verwaest T., Trouw K., De Nocker L., Couderé K. 2008. An Integrated Master Plan for Flanders Future Coastal Safety, Proceedings of the 31st International Conference on Coastal Engineering 2008, 31 August - 5 September 2008, Hamburg (Germany), pp. 4017 - 4028.

Verwaest T., Van der Biest K., Vanpoucke P., Reyns J., Vanderkimpen P., De Vos L., De Rouck J., Mertens, T. 2008. Coastal flooding risk calculations for the Belgian coast, Proceedings of the 31st International Conference on Coastal Engineering 2008, 31 August - 5 September 2008, Hamburg (Germany), pp. 4193 - 4201.

http://www.chainofsafety.com. Basic Document for a Transnational Contingency Plan Coastal Flooding, combined report. 